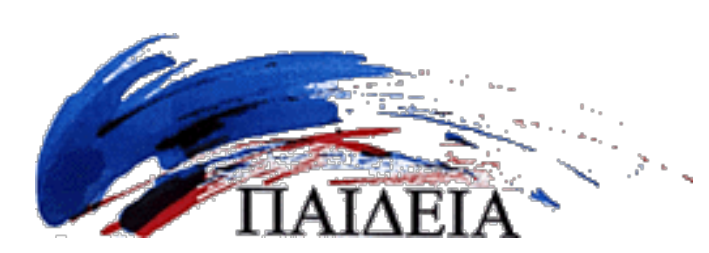

Philosophy and the Environment

\title{
Environmental Diversity and the Value of the Unusual $(1)$
}

\author{
Jason Kawall \\ Brown University \\ Jason_Kawall@brown.edu
}

\begin{abstract}
It is commonplace to call for the protection of environmental diversity. I develop an often overlooked reason for preserving diversity: we should preserve diversity in order to preserve the unusual. I show that we do in fact value the unusual, and that we should value the unusual (pace Rolston and Russow). Recognizing the value of the unusual provides a foundation for valuing species not otherwise considered valuable.
\end{abstract}

It is commonplace to call for the protection of environmental diversity. We wish to preserve species of animals, plants, birds, and so on, and the various habitats which support them. A number of compelling reasons have been put forth for valuing such diversity. For example, it has been argued that we should value the preservation of species as we may come to find, at some future point, that certain species can be used in important products. Other species, even if they are not themselves economically valuable, may be of value insofar as they interact with, and support the survival of, economically valuable species. Furthermore, a certain degree of biological diversity is required to help protect us against massive ecological disaster. (2)

Others have argued that we should value environmental diversity as a source of aesthetic values - beautiful species, sublime wildernesses, and so on. (3) Diversity provides us with 
a wide range of objects for various sciences. We also enjoy recreational activities in wilderness areas - another source of value. (4) Finally, we might claim that we should particularly value endangered species due to their rarity - much as collectors value rare books or recordings. (5)

While I believe these to be excellent reasons for valuing environmental diversity, in this paper I wish to isolate and develop an additional, surprisingly overlooked reason for valuing environmental diversity. I propose that a key reason that we value such diversity is that we value the unusual in general. My procedure will be to show that we do, in fact, value the unusual. I will then argue that we should value the unusual. Finally, I will show that focusing on this value allows us to understand our intuitions concerning a number of test cases.

\title{
1. Diversity and the Unusual
}

We can best begin to isolate the value we place on the unusual by considering concrete examples. First, consider this brief excerpt from Thoreau's Walden:

\begin{abstract}
One day when I went out to my wood-pile, or rather my pile of stumps, I observed two large ants, the one red, the other much larger, nearly half an inch long, and black, fiercely contending with each other. Having once got hold they never let go, but struggled and wrestled and rolled on the chips incessantly. Looking farther, I was surprised to find that the chips were covered with such combatants, that it was not a duellum, but a bellum, a war between two races of ants, the red always pitted against the black, and frequently two red ones to one black. The legions of these Myrmidons covered all the hills and vales in my woodyard, and the ground was already strewn with the dead and the dying, both red and black. It was the only battle which I have witnessed, the only battle-field I ever trod while the battle was raging. (6)
\end{abstract}

Thoreau's description of the battle goes on for a number of pages. Clearly, Thoreau is quite fascinated by this battle and is absorbed in observing it. His long description of the scene suggests that he also expects his readers to be intrigued. Consider next the following facts about giraffes, taken from a popular book of "nature facts":

They have bulgy eyes (and use them to see well in all directions), hairy lips, a tongue as long as 18 inches (convenient for curling around leaves), and a 25 pound heart for pumping blood to their extremities. They often eat more than 125 pounds of vegetation every day [...] When they bend down to get a drink of water, which they can go days without, special valves close to prevent a huge rush of blood to their brains, and their legs spread as if to split. (7)

I would now like to show that our intrigue and curiosity in the face of these descriptions 
(and, of course, others like them) suggest a value for environmental diversity which does not seem to be adequately accounted for in recent literature on this subject.

Clearly, we derive pleasure from experiencing and learning about the natural world. In some cases this is due to a creature or environment being beautiful, in others because it is rare. But frequently our intrigue is simply due to our finding a creature or environment unusual. Ants are not rare, nor are they beautiful, yet they arouse our interest. Giraffes are both rarer and perhaps more beautiful than ants, but our interest seems to be pushed primarily by their unique appearance and unusual features. We fascinated by the giraffe's long neck and gangly legs, regardless of its beauty (or lack thereof). In preserving natural diversity we preserve unusual species and environments.

Our fascination with the unusual in the natural world is an aspect of our broader interest in the unusual, tout court. This interest is reflected in the existence of museums and galleries which frequently display unusual objects, even if they are not beautiful. The Guiness Book of World Records, and various tabloids also reflect this interest, albeit in a less appealing context. The value we place on the unusual in nature is shown by the large number of people who frequent zoos and parks, and the popularity of documentaries and books on living creatures and their unusual means of capturing prey, attracting a mate, and so on.

Thus, we do value the unusual and the unique - both the manmade and the natural. Still, we may ask whether or not this is a value we should have. After all, there have been cultures which have valued such things as racial purity or the institution of slavery. Clearly, the mere fact that we value something is not sufficient to answer the normative question of whether a given value is appropriate.

\section{Should We Value The Unusual?}

First, let us consider whether there are any sound reasons for holding that we should not value the unusual. Consider the following argument from Lily-Marlene Russow:

Some appeals to intrinsic value [of species] are grounded in the intuition that diversity itself is a virtue. If so, it would seem incumbent upon us to create new species wherever possible, even bizarre ones that would have no purpose other than to be different. Something other than diversity must therefore be valued. (8)

While Russow's argument is explicitly presented against valuing diversity for its own sake, the point could be applied to valuing the unusual. Wouldn't valuing the unusual force us to create new, unusual species with no purpose other than to be unusual? 
Holmes Rolston III presents a similar argument in a recent book: Diversity is regularly valuable; "variety is the spice of life." Diversity is not, however, ipso facto a value. Were a university to receive an applicant from a foreign country, a young prince who wished to bring along his personal slave, would the university permit this, on grounds that it would add diversity? No, because justice is more important than diversity. Added perversity is not desirable diversity. Diversity is not valuable simply for its own sake. (9)

Both arguments suggest that if we value diversity or the unusual for its own sake (i.e. intrinsically), we will be forced into valuing things which it seems we do not want to value - randomly creating odd species, or unusual, immoral practices. The conclusion is that we therefore cannot value diversity or the unusual for its own sake.

However, these arguments do not support the strong conclusion that Russow and Rolston wish to draw. These arguments simply show that we must balance the intrinsic value we place on the unusual with other values. As Rolston himself notes, justice can override the value we place on the unusual, as in the case of the foreign prince with a personal slave. We shouldn't create new, unusual species which will not have a suitable environment, or will suffer enormously, or if the creation of the species will take up funds better spent on other projects, and so on. But none of this shows that we don't value the unusual intrinsically it only shows that this value can be overidden by other values.

We can clarify this point by considering some additional cases. Imagine that a house is burning down and a person is forced to choose between saving a beautiful painting and a young child. Surely we believe that the person ought to save the child and not the painting. But this does not yet show that we do not value the beautiful intrinsically - it merely shows that this value is only one value amongst many, and that it can be overidden. Susan Wolf has argued that moral saints would lead an impoverished life, (10) but again this suggests only that moral values may need to be balanced with other values, not that we don't value morality intrinsically. Indeed, it seems clear that we do value the beautiful and the moral intrinsically, and I suggest that, similarly, we value the unusual intrinsically. We only have to bear in mind that these values, even if intrinsic need to be balanced properly.

Are there other reasons to believe that we should not value the unusual? Perhaps valuing the unusual is 'shallow', and thus not desirable. We can imagine a time not long ago when people would crowd to see so-called 'freakshows'. They went to see the unusual, but this seems a dubious thing to value. It seems that valuing the unusual may simply be a matter of pointing and gawking at things with which we are not familiar. 
In response, we should again consider a specific example. There are people who have only a shallow appreciation of music or other arts. Perhaps they only listen to maudlin melodies or the latest hit singles. They may appreciate the beauty of the music to some extent, but their appreciation seems quite shallow. On the other hand, there will be listeners who become knowledgeable about music and composers, can identify various compositional structures, modalities, and so on. Their appreciation of music will likely be much richer and admirable.

I believe a similar range of possibilities exists when we consider the appreciation of the unusual. At its shallowest, it may involve nothing more than a simple-minded gawking at something an individual does not understand. But we can move beyond this, just as we move beyond shallow aesthetic appreciation. In its more refined forms our appreciation of the unusual creates a sense of wonder and fascination within us. We come to desire an understanding of what is presented to us. We may develop something of a love for certain unusual objects. Thoreau's absorption in the ants' battle is hardly shallow.

These last considerations point to positive values for appreciating the unusual. We derive pleasure from witnessing the unusual. We are often inspired to learn about the objects of our fascination. The unusual gives us stories and information we can share with others. When we are entranced by the unusual in nature we gain a respect for nature and its workings - be they guided by God or by natural laws alone.

I hope to have shown that valuing the unusual is not a shallow value, nor must it be merely instrumentally valuable. Rather, we merely need to bear in mind that the value we place on the unusual can be overriden by other values. In addition, there are positive reasons for valuing the unusual-we derive pleasure and fascination from experiencing it, we can be inspired by it, and so on. Thus, I take it that we should value the unusual.

\section{Consequences of Valuing the Unusual}

If the unusual is recognized as valuable, a number of intuitive consequences result when we consider various test cases, and when we compare this value to other values which have been posited for protecting natural diversity.

First, let us compare valuing the unusual with valuing aesthetic qualities. Russow maintains that there are some species which, by no stretch of the imagination, are aesthetically significant. But aesthetic value can cover a surprising range of things: a tiger may be 
simply beautiful; a blue-whale is awe-inspiring; a bird might be decorative; an Appaloosa is of interest because of its historical significance; and even a drab little plant may inspire admiration for the marvelous way it has been adapted to a special environment. Even so, there may be species such as the snail darter that simply have no aesthetic value. In these cases, lacking any alternative we may be forced to the conclusion that such species are not worth preserving. (11) First, notice that valuing the unusual provides us with reason to preserve the snail darter (and other species or environments) while valuing aesthetic qualities alone may not. The snail darter is unusual in being found only in a particular body of water in Tennessee. Many creatures are not beautiful, but are unusual. The platypus is hardly beautiful, but it is quite unusual, and as such is worth protecting. The two values complement each other. (12)

A second point to note is that Russow seems to extend the term 'aesthetic' too far. Being of historical interest is not an aesthetic value. Drab little plants are not aesthetically valuable - if their adapting to a special environment is valuable, it is because the environment and the adaptations are unusual. Thus, valuing the unusual (i) allows us to value creatures and environments which are not aesthetically valuable, and (ii) allows us to avoid extending the notion of aesthetic value beyond its intuitive scope.

Next, we can compare valuing the unusual and valuing the rare. Prima facie, it seems that these two notions should be intimately linked. The unusual cannot be the commonplace. Still, while the unusual and the rare are closely linked, there are differences. Consider a subspecies of ants which is limited to a few small colonies, but which differs from other related ants only in having slightly longer legs. Compare this to (let us imagine) a relatively large, healthy population of elephants. I would suggest that the elephants are more unusual than the subspecies of ants, even while the ants are rarer than the elephants. There are few creatures the size of elephants, or with trunks like elephants, and so on. On the other hand, there would be many subspecies of ants which seem very similar to the subspecies in question. Essentially, the difference between the two groups of creatures is that the ants are rare only in terms of population, while the elephants are rare in terms of species characteristics.

This difference between the unusual and the merely rare (in terms of population) is quite important. For valuing the unusual allows us to value species which are unlike most others, even if such species have large populations. If we valued only population rarity we would have little grounds for protecting species until they became endangered. This seems to be a good consequence of valuing the unusual - surely we want to value unique species before 
they become endangered. On the other hand, we should notice that becoming rare in terms of population is also a way of becoming unusual. There will be few opportunities to experience such a species. When we discover that there is only a small number of a species left our curiousity will tend to be piqued. It has become unusual.

It may be suggested that if a species is common (in terms of population) then it cannot be considered unusual because there are too many tokens of the type, too many members of the species. This can be seen to be mistaken, however, if we focus on an example. Consider the music of a composer such as John Cage or Philip Glass. Such music is very unusual, and remains unusual despite the thousands of compact discs (tokens) recorded of it. The music is unusual compared to other music, regardless of the number of recordings made of it. Similarly, an unusual species will be unusual compared to other species, regardless of the number of members of the species.

Rolston writes the following concerning rare (in terms of population) species:The rare species offer promise and memory of an inventive natural history. They do pique our curiousity; they are exotic and entertaining because they are rare. But that does not yet get at their real worth, which is that they are extraordinary manifestations of survival. (13)

In response to this, I would make two points. First, rare species are exotic and entertaining because they are unusual, and one reason that they are unusual is that they are rare. Second, Rolston suggests that the real value of rare species lies in their being "extraordinary manifestations of survival". I suggest that this can be captured by valuing the unusual - to be an extraordinary manifestation of survival is to be an unusual or unique manifestation of survival. Having an unusual method of survival in difficult circumstances is yet another way of being unusual.

Thus we can see that our valuing of the unusual provides important additional grounds for valuing environmental diversity. It supports our intuition that we should value many species that are not aesthetically valuable. It grounds our intuition that we should value species with unusual characteristics even if they are not endangered. On the other hand, it also captures the intuition that we should value species which are rare in terms of population. We value the unusual and we should value the unusual; recognition of this is a crucial step in coming to understand the full value of environmental diversity.

\section{Notes}


(1) I would like to thank Sarah Wright and Jennifer Lackey for helpful comments.

(2) An excellent presentation of such arguments, with strong empirical support can be found in Bryan G. Norton, "On the Inherent Danger of Undevaluing Species" in The Preservation of Species, ed. Bryan G. Norton (Princeton: Princeton University Press, 1986) 110-37.

(3) See, for example, Lily-Marlene Russow, "Why Do Species Matter?," Environmental Ethics 3 (1981), 101-12; Richard Cartwright Austin, "Beauty: A Foundation for Environmental Ethics," Environmental Ethics 7 (1985), 197-208; and J. Baird Callicott, "On the Intrinsic Value of Nonhuman Species" in Norton (1986), 138-72.

(4) For discussion of these values (and others), see Holmes Rolston III, Conserving Natural Value (New York: Columbia University Press, 1994), 134-41.

(5) Alastair S. Gunn considers (and ultimately rejects) this sort of claim in his "Why Should We Care about Rare Species?," Environmental Ethics 2 (1980), 19-37.

(6) Henry David Thoreau, Walden and Other Writings, ed. Joseph W. Krutch (New York: Bantam Books, 1977), 274.

(7) Jeanne K. Hanson and Deane Morrison, Of Kinkajous, Capybaras, Horned Beetles, and Seladangs (New York: HarperCollins Publishers, 1991), 238-9.

(8) Russow, 109.

(9) See Rolston, 39.

(10) Susan Wolf, "Moral Saints," Journal of Philosophy 79 (1982), 419-39.

(11) Russow, 109-10.

(12) That is to say, I am not maintaining that we should value diversity solely as a means to the unusual. There are a number of strong reasons for valuing diversity, but valuing the unusual provides grounds for valuing species which are not be captured by other values.

(13) Rolston, 53. 


\section{Top of page}

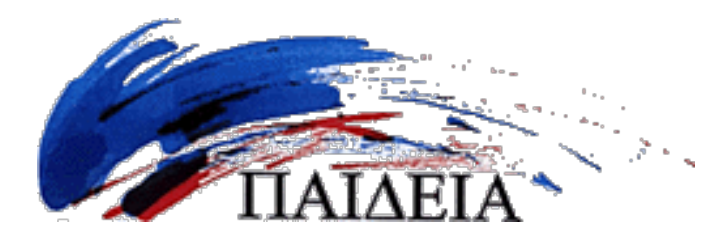

Home

Paideia logo design by Janet L. Olson.

All Rights Reserved 